\title{
The physiology of stopover decisions: food, fat and zugunruhe on a Mediterranean island
}

\author{
Sara Lupi ${ }^{1,2}$ - Julia Slezacek ${ }^{1} \cdot$ Leonida Fusani $^{1,3}$
}

Received: 4 February 2019 / Revised: 17 July 2019 / Accepted: 18 July 2019 / Published online: 5 August 2019

(c) The Author(s) 2019

\begin{abstract}
The study of avian migration physiology has advanced substantially in the past few decades, yet despite the key role of migratory stopovers in influencing total migration time, our knowledge on the physiological control of this crucial stage is still scarce. Research in stopover physiology has recently taken new directions and uncovered new mechanisms which help us understand how multiple internal factors, such as body condition or fuelling rate, interact with one another to trigger the rapid metabolic and behavioural switches that underlie stopover decisions. In this paper, we review a series of studies that our group conducted during the last 14 years on the island of Ponza (Italy), an important stopover site for thousands of small passerines migrating from Africa to Europe in spring. Focusing on nocturnally migrating passerines, we first discuss the pivotal role of fuel stores in decision-making processes during stopover. We then present recent research on the effects of food availability and fuel accumulation on behaviour shown by migrants at stopover places. Finally, we summarise recent findings on the hormonal factors that participate in controlling the switch between non-migratory and migratory state. Although the review is focused on our studies, we include recent work by other groups in this field.
\end{abstract}

Keywords Avian migration $\cdot$ Fat stores $\cdot$ Food availability $\cdot$ Refueling $\cdot$ Ghrelin $\cdot$ Hormones

\section{Introduction}

In the last decade, the study of the physiology of avian migration has made substantial progress. Important advances were made in understanding behaviour and physiology during migration thanks to integrated, crossdisciplinary approaches. The fast pace of advancement in

Communicated by N. Chernetsov.

This article is a contribution to the Topical Collection 27th International Ornithological Congress, Vancouver, Canada, 19 to 26 August 2018.

Sara Lupi

sara.lupi@vetmeduni.ac.at

1 Konrad-Lorenz Institute of Ethology, University of Veterinary Medicine, Vienna, Savoyenstrasse 1, 1160 Vienna, Austria

2 Department of Biology, Advanced Facility for Avian Research, University of Western Ontario, 1151 Richmond Street, London, Ontario N6A5B7, Canada

3 Department of Cognitive Biology, University of Vienna, Althanstrasse 14, 1090 Vienna, Austria animal-tracking technologies, e.g. miniaturised light-level geolocators and automated radiotelemetry systems, has boosted research on routes, stopover sites, and wintering grounds of small migratory birds.

When we think about avian migration, we wonder about the incredible ability of birds to fly non-stop over deserts, oceans, and continents, often at night as for most songbirds. But equally impressive is the capacity of some species to rapidly switch from mainly anabolic type of metabolism and purely diurnal activity during stopovers to mainly catabolic type of metabolism and nocturnal activity during flights. Migration timing is strongly driven by an internal spatiotemporal program governed by endogenous rhythms, which is modulated during migration by a large number of extrinsic factors, e.g. atmospheric conditions (e.g. wind, air pressure and precipitation), food abundance and predation risk, and intrinsic factors, e.g. fuel stores, fuel accumulation and hormonal factors (Jenni and Schaub 2003; Dänhardt and Lindström 2001; Smith and McWilliams 2014; Müller et al. 2016; Wingfield et al. 1990; Goymann et al. 2018; Schmaljohann and Eikenaar 2017). Extrinsic and intrinsic factors shape birds' decisions during migratory flights as well as during stopovers, with an influence that varies seasonally 
and throughout the migration period (Smith and McWilliams 2014). With stopover decisions, we refer to behavioural switches during stopovers such as resting/sleeping versus being active or foraging versus being vigilant, and to departure decisions. What intrinsic factors regulate the decision to interrupt resting and food searching at a stopover site in favour of commencing the next migratory flight? Recent studies on this topic have provided a better understanding not only of the physiology of stopover, but also of the overall regulation and timing of avian migration. Indeed, time spent at stopover sites largely contributes to the speed of migration (Hedenström and Alerstam 1997; Schmaljohann 2018), and individual variation in stopover duration is the major determinant of individual duration of migration overall.

Our group has been focusing on the stopover physiology of nocturnally migrating passerines to investigate the mechanisms underlying migratory behaviour and decisionmaking processes. Specifically, we have conducted extensive research on the involvement of intrinsic factors, such as body condition, food intake, and hormones, in the mechanisms that trigger the decision of migrants to either prolong their stopover or resume migration. Since 2005, we have been taking advantage of the large number of migrants arriving on the island of Ponza (Italy, $40^{\circ} 50^{\prime} \mathrm{N}, 12^{\circ} 58^{\prime} \mathrm{E}$; surface area $9.87 \mathrm{~km}^{2}$ ) during spring migration.

This review aims to provide a summary of our research on the island of Ponza on nocturnally migrating passerines. We will present our main results on how a number of physiological factors affect stopover decisions. Specifically, we will first discuss the major role of body condition during stopover in the urge to resume migration. We will then discuss the role of food availability and energy accumulation during stopovers. Finally, we will summarise our current knowledge on the involvement of some hormonal factors, in particular the appetite-regulating hormone ghrelin, on stopover decisions. We do not attempt to present a comprehensive overview of all internal factors underlying bird migration; instead we focus on those factors that our group has investigated extensively. For this reason, our discussion will not include external factors (e.g. weather conditions or predation risk) and will be based mostly on passerine migrants. Nevertheless, we will include in the discussion a few studies of other groups that helped us better understand the topics presented (Table 1).

\section{Energy reserves: a look at the root of stopover decisions}

In the last century, a number of studies provided evidence that the extent of energy stores carried by individuals explained a large part of the variation in stopover behaviour. Beginning in the 1980s, important advances were made by field studies that assessed minimum stopover duration based on observations and capture-recapture models (Bairlein 1985; Biebach 1985; Biebach et al. 1986). The discovery that the intensity of nocturnal restlessness (thereafter zugunruhe) in captive nocturnal migrants reflected the duration of migration of free-living birds of the same species (Berthold 1973) prompted the development of laboratory research on stopover physiology and behaviour. Laboratory studies on captive migratory songbirds demonstrated that the suppression of zugunruhe in response to a food availability protocol simulating a refueling stopover after a long migratory flight was modulated by the extent of fat reserves and body mass of an individual, confirming a major role of energy reserves in decision-making at stopover sites (Biebach 1985; Gwinner et al. 1988; Fusani and Gwinner 2004).

Until two decades ago, the study of the physiology of migration involved either field-based research consisting of capture and immediate release (or euthanasia) of free-living birds, or laboratory-based research consisting of long-term caging of birds, which were hand-raised in most cases. What was missing was the study of free-living migratory birds under controlled conditions, but with a setup that minimised the effects of captivity on their physiological and behavioural responses. At the beginning of the 2000s, Leonida Fusani, Wolfgang Goymann, and their collaborators developed a novel approach based on a combination of classical laboratory and field methods (Fusani et al. 2009). Free-living birds caught at a stopover site are temporarily taken into captivity in individual cages at the field site for one or two nights and then released. At capture, morphological, physiological, and demographic variables are recorded, and samples can be collected for genetic or physiological investigation. During caging, the behaviour of the animals is recorded with infrared sensors or video cameras to measure behavioural variables such as locomotor activity, food intake, rest, and zugunruhe. A number of studies have confirmed that variables recorded in this set-up are a good proxy for behaviours that are very difficult, if not impossible, to record in small free-living birds; for example, zugunruhe is an excellent indicator of migratory disposition (Berthold 1973) and of the actual likelihood of departure in the wild (Eikenaar et al. 2014b). By using this experimental approach, which we called 'overnight', we can control the confounding effects of a number of factors such as weather condition, predation risk, and local disturbances. Capture and temporary captivity are likely to have individual effects on the behaviour and physiology of the experimental birds, but these effects can be taken care of statistically thanks to the availability of large sample sizes that allow us to control random noise in the results.

This innovative approach has proved to be useful in uncovering new aspects of avian stopover physiology and providing quantitative evidence in support of the initial hypothesis that fuel reserves determine stopover duration 
Table 1 Main results of recent studies of our group and other researchers on some of the physiological factors that modulate stopover decisions of nocturnally migrating passerines

\begin{tabular}{|c|c|c|}
\hline Reference & Species & Main results \\
\hline Schaub et al. (2008) & $\begin{array}{l}\text { Willow Warbler (Phylloscopus trochilus) } \\
\text { Pied Flycatcher (Ficedula hypoleuca) } \\
\text { Reed Warbler (Acrocephalus scirpaceus) }\end{array}$ & $\begin{array}{l}\text { Negative and highly positive fuel deposition rates increased } \\
\text { emigration probability }\end{array}$ \\
\hline Fusani et al. (2009) & $\begin{array}{l}\text { Garden Warbler (Sylvia borin) } \\
\text { Common Whitethroat (Sylvia communis) } \\
\text { Whinchat (Saxicola rubetra) }\end{array}$ & $\begin{array}{l}\text { Body condition positively correlated with zugunruhe; leaner } \\
\text { birds showed higher variability in zugunruhe }\end{array}$ \\
\hline Goymann et al. (2010) & Garden Warbler & Subcutaneous fat stores predicted minimum stopover duration \\
\hline Fusani et al. (2011) & Garden Warbler & $\begin{array}{l}\text { Zugunruhe positively correlated with body condition but not } \\
\text { with melatonin levels; availability of food positively affected } \\
\text { zugunruhe; zugunruhe not affected by experimental elevation } \\
\text { of melatonin levels }\end{array}$ \\
\hline Fusani et al. (2013) & $\begin{array}{l}\text { Eurasian Blackcap (Sylvia atricapilla) } \\
\text { Garden Warbler }\end{array}$ & $\begin{array}{l}\text { Melatonin treatment significantly increased intensity of zugun- } \\
\text { ruhe; zugunruhe positively correlated with body condition; } \\
\text { tendency of food availability to increase zugunruhe; body } \\
\text { mass change related to food availability }\end{array}$ \\
\hline Eikenaar et al. (2014b) & Northern Wheatear (Oenanthe oenanthe) & $\begin{array}{l}\text { Zugunruhe was found to be an accurate proxy for the motivation } \\
\text { to migrate }\end{array}$ \\
\hline Eikenaar et al. (2014a) & Northern Wheatear & $\begin{array}{l}\text { Daily corticosterone levels positively correlated with zugunruhe } \\
\text { of the night after blood sampling }\end{array}$ \\
\hline Smith and McWilliams (2014) & Hermit Thrushes (Catharus guttatus) & $\begin{array}{l}\text { Fuel stores predicted movements during stopover and minimum } \\
\text { stopover duration }\end{array}$ \\
\hline Deppe et al. (2015) & $\begin{array}{l}\text { Swainson's Thrush (Catharus ustulatus) } \\
\text { Wood Thrush (Hylocichla mustelina) } \\
\text { Red-eyed Vireo (Vireo olivaceus) }\end{array}$ & $\begin{array}{l}\text { Fat stores modulated the effects of extrinsic factors on departure } \\
\text { decisions }\end{array}$ \\
\hline Lupi et al. (2016) & $\begin{array}{l}\text { Black Redstart (Phoenicurus ochruros) } \\
\text { European Robin (Erithacus rubecula) } \\
\text { Stonechat (Saxicola torquata) }\end{array}$ & $\begin{array}{l}\text { Body condition positively correlated with zugunruhe, especially } \\
\text { before midnight }\end{array}$ \\
\hline Lupi et al. (2017) & $\begin{array}{l}\text { Garden Warbler } \\
\text { European Robin }\end{array}$ & $\begin{array}{l}\text { In Garden Warblers, but not in robins, food intake correlated } \\
\text { positively with zugunruhe and negatively with diurnal activity }\end{array}$ \\
\hline Schmaljohann and Eikenaar (2017) & Northern Wheatear & Fuel deposition rate negatively affected departure probability \\
\hline Eikenaar et al. (2017) & Northern Wheatear & $\begin{array}{l}\text { Corticosterone predicted departure likelihood and time; birds } \\
\text { with high corticosterone departed earlier than birds with low } \\
\text { levels on the night after capture }\end{array}$ \\
\hline Goymann et al. (2017) & Garden Warbler & $\begin{array}{l}\text { Ghrelin positively correlated with fat stores; manipulation of } \\
\text { unacylated ghrelin increased zugunruhe and suppressed food } \\
\text { intake, especially in lean birds }\end{array}$ \\
\hline Eikenaar et al. (2018) & Common Blackbird (Turdus merula) & $\begin{array}{l}\text { Corticosterone and ghrelin did not correlate. Ghrelin did not } \\
\text { reflect fat stores and did not predict departure likelihood }\end{array}$ \\
\hline
\end{tabular}

(Bairlein 1985; Biebach 1985). With the overnight approach, we can test the influence of a number of physiological factors on stopover decisions without the need for assumptions about the date and time of arrival at the stopover site. The relationship between a physiological parameter such as body condition and zugunruhe on the day of capture, which is not necessarily the arrival day, can be used to estimate the likelihood of resuming migration in a bird with a similar body condition. As shown in this review, this approach has been extremely effective in revealing elements that are part of the complex mechanisms underlying the decision to prolong stopover or resume migration during spring migration.

In two studies on a few species of short- and long-distance nocturnally migrating songbirds, we found that the intensity of zugunruhe positively and strongly reflects body condition (Fusani et al. 2009; Lupi et al. 2016). Body condition was calculated as the principal component extracted from measurements of body mass, fat score, and muscle score, as determined following European ringing standards (Bairlein 1995): the higher the index, the better the body condition of the bird. Thus, the results of these two studies revealed that in both short- and long-distance migrants, fuel resources are a major determinant of stopover behaviour, suggesting that these species use similar stopover strategies after crossing an ecological barrier (Mediterranean Sea: about $500 \mathrm{~km}$ ) regardless of whether they migrate short or long distances. In another study, using manual radiotelemetry on the small neighbour island of Ventotene $\left(40^{\circ} 47^{\prime} \mathrm{N}, 13^{\circ} 24^{\prime} \mathrm{E}\right.$, surface 
area $1.75 \mathrm{~km}^{2}$ ), we showed that the extent of the subcutaneous fat stores, the main determinant of body condition, strongly influences actual stopover decisions (Goymann et al. 2010). In this study, fat and lean Garden Warblers (Sylvia borin), caught on the island on the same days and experiencing constant, optimal weather conditions throughout the duration of the experiment, showed different stopover times, with a measured minimum stopover duration of $8.8 \mathrm{~h}$ in fat birds and $41.3 \mathrm{~h}$ in lean birds (Goymann et al. 2010). These results are consistent with the knowledge that fatty acids are the main source of energy in migrating birds (McWilliams et al. 2004; Guglielmo 2010). Another radiotelemetry study conducted on a group of migratory songbird species at a stopover site preceding the crossing of the Gulf of Mexico demonstrated that energy reserves modulate the extent to which extrinsic factors-such as atmospheric humidity and wind conditions-affect stopover and crossing behaviour, confirming the complexity of decision-making processes during migration (Deppe et al. 2015). Similarly, Smith and McWilliams (2014) showed in a telemetry experiment that in hermit thrushes (Catharus guttatus), the speed of the continuation of migration is influenced by experimentally manipulated fat stores during autumn stopover: birds with higher fat scores left the stopover site earlier than leaner individuals. Two radiotelemetry experiments conducted on European Robins (Erithacus rubecula) during spring and fall stopovers on the Courish Spit, Eastern Baltic, however, found no association between body condition and stopover duration (Tsvey et al. 2007; Chernetsov and Mukhin 2006), illustrating that the mechanisms underlying decision-making during migration are likely influenced by seasonal, speciesspecific, and site-specific factors.

\section{Food availability and food intake as major contributors to shaping stopover behaviour}

One of the prime characteristics of an ideal stopover site is the existence of abundant food resources that can be used to replenish depleted internal fuel stores to power the next flight segment, especially if birds have just undertaken a long non-stop flight. The decision of whether or not to prolong the stopover may thus be influenced by the availability and intake of food suitable for rebuilding fuel stores. Already in the 1990s, Alerstam and Lindström predicted that the rate of energy accumulation during stopovers was the main determinant of the departure decision for time-minimising birds (Alerstam and Lindström 1990). A number of studies that measured food intake in captive migratory birds found that stopover decisions were triggered by the interaction of actual fuel stored and rate of fuel accumulation. In a fasting and refeeding experiment, zugunruhe dropped during refuelling in Garden Warblers and Spotted Flycatchers (Muscicapa striata), and it eventually increased when fat stores reached a threshold (Gwinner et al. 1985; Biebach 1985). Furthermore, Lindström (2002) pointed out that food availability at stopover sites was the most common factor limiting the rates at which avian migrants could refuel, and that if fast fuel deposition rates were desired, birds should be under strong selection pressure to choose stopover sites with optimal food availability. Indeed, the fuel deposition rate is increased in birds that are experimentally supplemented with food during stopover compared to individuals without increased food availability, and the fuel deposition rate further correlates with the spatial and temporal distribution of food resources (reviewed in Lindström 2002). In more recent years, a fieldbased study investigated the relationship between the rate at which birds accumulate energy at stopover sites (measured as body mass change) and departure decision in a number of migratory passerine species (Schaub et al. 2008). The authors found that birds with low or high fuel deposition rates, causing a decrease in fuel stores or high-rate increase in fuel stores, left a stopover site earlier than birds experiencing a medium rate of energy accumulation (Schaub et al. 2008). A field-based study on Northern Wheatears (Oenanthe oenanthe) found similar results and confirmed the importance of the rate of energy stored in decisions made at stopover sites (data collected in Schmaljohann and Dierschke 2005; see new analysis in Schmaljohann and Eikenaar 2017). Specifically, Schmaljohann and colleagues showed that the higher the rate of fuel deposition, the lower the probability of a bird's departure. These studies suggest that birds use a simple set of rules: if they find little or no food, they leave quickly to search for better refueling sites; if they encounter high food abundance, they refuel rapidly and leave soon thereafter; if they find some but not abundant food, they stay as long as needed to reach the required amount of fuel stores (Schaub et al. 2008; Schmaljohann and Dierschke 2005; Schmaljohann and Eikenaar 2017).

In 2006-2008, we caught migrating Garden Warblers with intermediate body condition at our spring stopover field site on Ponza island and assigned individuals to either a food-restricted (no food) or ad libitum (30 g) food treatment for $24 \mathrm{~h}$. We found that the availability of food during the day increased zugunruhe in the following night. These results showed that the migrants' physiological condition during stopover and food availability at the site played a major role in the control of zugunruhe (Fusani et al. 2011). As confirmation of this, in another study we showed that caged Garden Warblers, which ate a higher amount of food during the first day of caging, increased their zugunruhe in the following night (Lupi et al. 2017). Furthermore, captive birds with higher food consumption and body condition generally showed higher zugunruhe (Lupi et al. 2017). In this study, we showed that not only food availability but also the actual amount of food eaten played an important role in expressing zugunruhe in temporarily caged migrating 
Garden Warblers. Our studies on food availability and food intake during simulated migratory stopovers highlight the existence of an interplay between food consumption and body condition that affects the decision-making processes related to leaving a stopover site or remaining and continuing refuelling. The relative importance of these factors is most probably influenced by aspects such as migratory strategy, the need to minimise time or energy expenditure, weather, and species-specific features of migratory behaviour.

\section{Hormones as triggers of physiological and behavioural adjustments during migration}

Since the 1990s, migration physiology research has tried to uncover the hormonal mechanisms that modulate behavioural responses to physiological status and processes such as depletion or accumulation of energy reserves. There have been significant steps forward in the understanding of the endocrine regulation of migration, particularly in relation to the spring stage (Wingfield et al. 1990; Cornelius et al. 2013; Watts et al. 2017). During migration, the oscillation in fat levels between the flight and refuelling cycles is centrally controlled by stimulatory and inhibitory neurons in the hypothalamus (Boswell 2005). An involvement of peripheral factors in the control of body condition and refueling during migration is enabled by direct exposure of the hypothalamus to several circulating hormones, e.g. glucocorticoids, ghrelin, insulin, and leptin (Boswell and Dunn 2015).

Most research aimed at understanding the hormonal mechanisms underlying migratory decisions has focused on a few hormonal pathways. It is well established, for example, that corticosterone stimulates locomotion in vertebrates (Landys et al. 2006). Recent studies have found that corticosterone baseline levels are associated with zugunruhe, departure likelihood, and nocturnal departure time in Northern Wheatears during fall migration (Eikenaar et al. 2014a, 2017), which suggests a role of corticosterone in promoting the onset of migration besides its action on mobilisation of energy from fat stores. A series of studies that began with the pioneering work of Eberhard Gwinner and colleagues, and continues today, has evidenced a role for the hormone melatonin in the control of the physiological adjustments that accompany the switch between stopover and resumption of migration (Gwinner et al. 1993; Fusani and Gwinner 2001, 2005). A direct effect of melatonin in inducing a reduction in zugunruhe has been demonstrated for autumn but not for spring migration (Fusani et al. 2011, 2013), suggesting that hormonal regulatory systems might differ between the two migratory stages. Alongside the established involvement of corticosterone and melatonin in controlling migratory behaviour, the extensive evidence for a primary role of fat stores in determining stopover decisions prompted us to explore further directions. We therefore started to study hormones that are involved in the regulation of food intake and energy storage to ascertain whether and how they influence migratory behaviour. The hormone ghrelin attracted our attention because of its known effects on food intake and appetite in vertebrates (Kaiya et al. 2007, 2009, 2013a, b). Little was known about the biological functions of ghrelin in birds apart from a few studies in domestic galliforms, which showed that in these birds, ghrelin reflects the nutritional state, inhibits food intake, and exerts regulatory functions for energy metabolism, such as down-regulation of the build-up of fats (Kaiya et al. 2009; Richards and McMurtry 2010; Geelissen et al. 2006; Buyse et al. 2009). We hypothesised that ghrelin acts on key migratory traits such as refueling behaviour and metabolic adjustments during stopover, and is therefore a determinant in the control of bird migration. Specifically, we investigated the association between fat stores and circulating levels of ghrelin in free-living Garden Warblers caught at our field site during spring migration (Goymann et al. 2017). In addition, we investigated the effects of ghrelin manipulation on zugunruhe and food intake in birds kept in registration cages overnight. Because circulating ghrelin has two forms, acylated and unacylated, we treated the experimental birds with either of these two forms of ghrelin, whereas the control birds received the vehicle only. We found that the plasma levels of acylated ghrelin reflected the extent of subcutaneous fat stores, with higher levels in birds with higher fat scores (Goymann et al. 2017). Moreover, treatment with unacylated ghrelin reduced food intake and stimulated zugunruhe, suggesting an action of this form of ghrelin on regulatory regions in the brain. This study provided the first evidence for an involvement of the hormone ghrelin in the control of migratory behaviour of passerine species and opened questions about the involvement of other orexic and anorexic hormones in the regulation of avian migration. So far, there has been only one other study that investigated the role of ghrelin in migratory birds. Eikenaar and colleagues (2018) used an automated radiotelemetry system to look at the relationship between ghrelin and corticosterone levels and departure timing in Common Blackbirds (Turdus merula) during autumn migration. Ghrelin did not reflect the extent of fat stores, did not correlate with corticosterone, and did not explain departure timing. These different results might be due to a number of factors, e.g. seasonal differences (spring vs autumnal migration) and/or species-specific differences. More research will be necessary to uncover the role of ghrelin during migration. We are currently investigating whether this hormone acts as a trigger for physiological adjustments such as activation of 


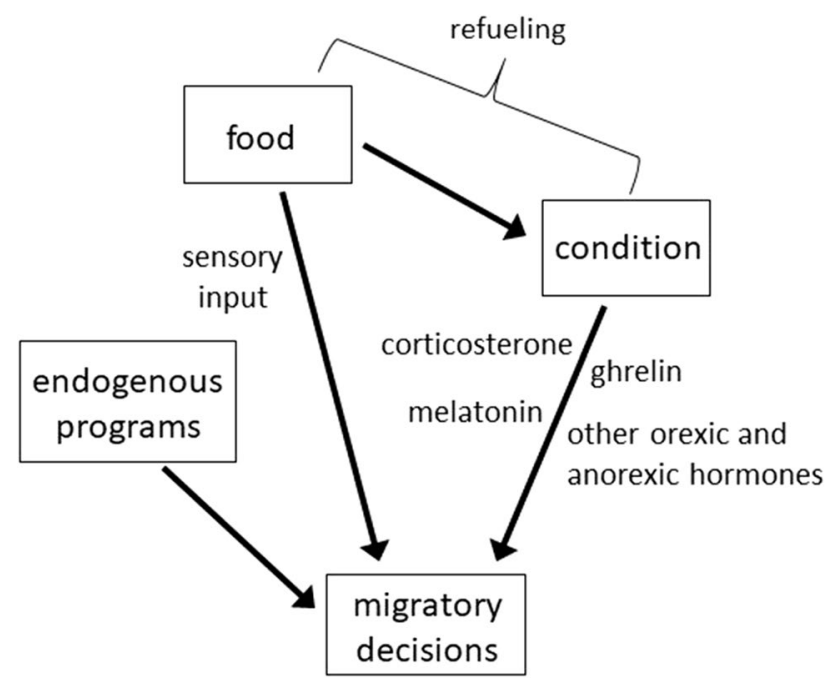

Fig. 1 Schematic drawing summarising the results of our research on some of the factors that modulate stopover decisions of nocturnally migrating passerines

fat catabolism and how it influences migratory behaviour of free-living birds.

\section{Conclusions}

In this review, we summarise how work from our group and other researchers has demonstrated a primary role of body condition, food availability, and energy stores accumulation in the regulation of stopover behaviour in nocturnally migrating passerines. Figure 1 shows a schematic drawing of our current understanding of regulation of stopover decisions in this group of birds. An important missing link to understanding these decisions in nocturnally migrating passerines is the influence of stopover site quality on stopover behaviour, and future studies should investigate birds' responses to different levels of food availability during stopover. Moreover, studies on the response to food availability of birds in intermediate conditions, which should be on the cusp between deciding to stay or leave a stopover site, could provide crucial insights into individual decision-making processes during migratory stopovers. We think that the gut hormone ghrelin can mediate the shift between non-migratory and migratory phenotypes across the migratory period and trigger metabolic and behavioural changes in response to the energy status of the bird. Research on avian orexic and anorexic hormones is still at an early stage and we will need to integrate disciplines such as genetics, biochemistry, and molecular biology to increase our knowledge on this class of hormones in birds.
Acknowledgements Open access funding provided by University of Veterinary Medicine Vienna. Research of our group presented in this review was made possible by the contributions of many students, personnel and volunteers in the field and laboratory. Since 2005, funding and support for our studies has come from the University of Ferrara, the Max Planck Institute for Ornithology, the MIUR-DAAD Vigoni Programme, the University of Vienna, and the University of Veterinary Medicine, Vienna. The ringing station in Ponza is operating within the long-term ringing project 'Piccole Isole' coordinated by Dr. Fernando Spina, Istituto Superiore per la Protezione e la Ricerca Ambientale.

\section{Compliance with ethical standards}

Conflict of interest The authors declare that they have no conflict of interest.

Open Access This article is distributed under the terms of the Creative Commons Attribution 4.0 International License (http://creativeco mmons.org/licenses/by/4.0/), which permits unrestricted use, distribution, and reproduction in any medium, provided you give appropriate credit to the original author(s) and the source, provide a link to the Creative Commons license, and indicate if changes were made.

\section{References}

Alerstam T, Lindström A (1990) Optimal bird migration: the relative importance of time, energy, and safety. In: Gwinner E (ed) Bird migration: physiology and ecophysiology. Springer, Berlin, pp 331-351

Bairlein F (1985) Body weights and fat deposition of Palaearctic passerine migrants in the central Sahara. Oecologia 66:141-146. https://doi.org/10.1007/Bf00378566

Bairlein F (1995) Manual of field methods. European-African Songbird Migration Network, Wilhelmshaven

Berthold P (1973) Relationships between migratory restlessness and migration distance in six Sylvia species. Ibis (Lond 1859) 115:594-599. https://doi.org/10.1111/j.1474-919x.1973.tb019 98.x

Biebach H (1985) Sahara stopover in migratory flycatchers: fat and food affect the time program. Experientia 41:695-697. https:// doi.org/10.1007/Bf02007727

Biebach H, Friedrich W, Heine G (1986) Interaction of body mass, fat, foraging and stopover period in trans-Sahara migrating passerine birds. Oecologia 69:370-379. https://doi.org/10.1007/Bf00377059

Boswell T (2005) Regulation of energy balance in birds by the neuroendocrine hypothalamus. J Poult Sci 42:161-181

Boswell T, Dunn I (2015) Regulation of the avian central melanocortin system and the role of leptin. Gen Comp Endocrinol 221:278-283. https://doi.org/10.1016/j.ygcen.2014.12.009

Buyse J, Janssen S, Geelissen S et al (2009) Ghrelin modulates fatty acid synthase and related transcription factor mRNA levels in a tissue-specific manner in neonatal broiler chicks. Peptides 30(7):1342-1347. https://doi.org/10.1016/j.peptides.2009.04.015

Chernetsov N, Mukhin A (2006) Spatial behavior of European robins during migratory stopovers: a telemetry study. The Wilson J Ornithol 118:364-373. https://doi.org/10.1676/04-134.1

Dänhardt J, Lindström A (2001) Optimal departure decisions of songbirds from an experimental stopover site and the significance of weather. Anim Behav 62(2):235-243. https://doi.org/10.1006/ anbe.2001.1749

Deppe JL, Ward MP, Bolus RT et al (2015) Fat, weather, and date affect migratory songbirds' departure decisions, routes, and time 
it takes to cross the Gulf of Mexico. Proc Natl Acad Sci USA 112(46):E6331-E6338. https://doi.org/10.1073/pnas.1503381112

Eikenaar C, Klinner T, Stöwe S (2014a) Corticosterone predicts nocturnal restlessness in a long-distance migrant. Horm Behav 66:324329. https://doi.org/10.1016/j.yhbeh.2014.06.013

Eikenaar C, Klinner T, Szostek KL, Bairlein F (2014b) Migratory restlessness in captive individuals predicts actual departure in the wild. Biol Lett 10:20140154. https://doi.org/10.1098/ rsbl.2014.0154

Eikenaar C, Müller F, Leutgeb C et al (2017) Corticosterone and timing of migratory departure in a songbird. Proc R Soc B 284:20162300. https://doi.org/10.1098/rspb.2016.2300

Eikenaar C, Hessler S, Ballstaedt E, Schmaljohann H, Kaiya H (2018) Ghrelin, corticosterone and the resumption of migration from stopover, an automated telemetry study. Physiol Behav 194:450 455. https://doi.org/10.1016/j.physbeh.2018.06.036

Fusani L, Gwinner E (2001) Reduced amplitude of melatonin secretion during migration in the blackcap (Sylvia atricapilla). In: Goos HJT, Rastogi RK, Vaudry H, Pierantoni R (eds) Perspectives in Comparative Endocrinology: Unity and Diversity. Menduzzi Editore, Sorento, Italy, pp 295-300

Fusani L, Gwinner E (2004) Simulation of migratory flight and stopover affects night levels of melatonin in a nocturnal migrant. Proc Biol Sci 271:205-211. https://doi.org/10.1098/rspb.2003.2561

Fusani L, Gwinner E (2005) Melatonin and nocturnal migration. Ann NY Acad Sci 1046:264-270. https://doi.org/10.1196/annal s.1343.024

Fusani L, Cardinale M, Carere C, Goymann W (2009) Stopover decision during migration: physiological conditions predict nocturnal restlessness in wild passerines. Biol Lett 5:302-305. https://doi. org/10.1098/rsbl.2008.0755

Fusani L, Cardinale M, Schwabl I, Goymann W (2011) Food availability but not melatonin affects nocturnal restlessness in a wild migrating passerine. Horm Behav 59:187-192. https://doi. org/10.1016/j.yhbeh.2010.11.013

Fusani L, Coccon F, Rojas Mora A, Goymann W (2013) Melatonin reduces migratory restlessness in Sylvia warblers during autumnal migration. Front Zool 10:79. https://doi. org/10.1186/1742-9994-10-79

Geelissen SME, Swennen Q, Van der Geyten S et al (2006) Peripheral ghrelin reduces food intake and respiratory quotient in chicken. Domest Anim Endocrinol 30(2):108-116. https://doi. org/10.1016/j.domaniend.2005.06.005

Goymann W, Spina F, Ferri A, Fusani L (2010) Body fat influences departure from stopover sites in migratory birds: evidence from whole-island telemetry. Biol Lett 6:478-481. https://doi. org/10.1098/rsbl.2009.1028

Goymann W, Lupi S, Kaiya H, Cardinale M, Fusani L (2017) Ghrelin affects stopover decisions and food intake in a long-distance migrant. Proc Natl Acad Sci USA. https://doi.org/10.1073/ pnas. 1619565114

Guglielmo CG (2010) Move that fatty acid: fuel selection and transport in migratory birds and bats. Integr Comp Biol Sep 50(3):336-345. https://doi.org/10.1093/icb/icq097

Gwinner E, Biebach H, V Kries I (1985) Food availability affects migratory restlessness in caged garden warblers (Sylvia borin). Naturwissenschaften 72:51-52. https://doi.org/10.1007/BF004 05336

Gwinner E, Schwabl H, Schwabl-Benzinger I (1988) Effects of fooddeprivation on migratory restlessness and diurnal activity in the garden warbler Sylvia borin. Oecologia 77:321-326. https://doi. org/10.1007/bf00378037

Gwinner E, Schwabl-Benzinger I, Schwabl H, Dittami J (1993) 2 hour melatonin profiles in a nocturnally migrating bird during and between migratory seasons. Gen Comp Endocrinol 90:119-124. https://doi.org/10.1006/gcen.1993.1066

Hedenström A, Alerstam T (1997) Optimum fuel loads in migratory birds: distinguishing between time and energy minimization. J Theor Biol 189:227-234. https://doi.org/10.1006/jtbi.1997.0505

Jenni L, Schaub M (2003) Behavioural and physiological reactions to environmental variation in bird migration. In: Berthold $\mathrm{P}(\mathrm{ed})$ Avian migration. Springer, Berlin, Heidelberg, pp 155-171

Kaiya H, Darras VM, Kangawa K (2007) Ghrelin in birds: its structure, distribution and function. Jpn Poult Sci 44:1-18

Kaiya H, Furuse M, Miyazato M, Kangawa K (2009) Current knowledge of the roles of ghrelin in regulating food intake and energy balance in birds. Gen Comp Endocrinol 163(1-2):33-38. https:// doi.org/10.1016/j.ygcen.2008.11.008

Kaiya H, Kangawa K, Miyazato M (2013a) Update on ghrelin biology in birds. Gen Comp Endocrinol 190:170-175

Kaiya H, Kangawa K, Miyazato M (2013b) What is the general action of ghrelin for vertebrates? Comparisons of ghrelin's effects across vertebrates. Gen Comp Endocrinol 181:187-191

Landys MM, Ramenofsky M, Wingfield JC (2006) Actions of glucocorticoids at a seasonal baseline as compared to stress-related levels in the regulation of periodic life processes. Gen Comp Endocrinol 148(2):132-149. https://doi.org/10.1016/j.ygcen .2006 .02 .013

Lupi S, Goymann W, Cardinale M, Fusani L (2016) Physiological conditions influence stopover behaviour of short-distance migratory passerines. J Ornithol 157:583-589. https://doi.org/10.1007/s1033 6-015-1303-5

Lupi S, Maggini I, Goymann W et al (2017) Effects of body condition and food intake on stop-over decisions in Garden Warblers and European Robins during spring migration. J Ornithol 158:989. https://doi.org/10.1007/s10336-017-1478-z

McWilliams SR, Guglielmo C, Pierce B, Klaassen M (2004) Flying, fasting, and feeding in birds during migration: a nutritional and physiological ecology perspective. J Avian Biol 35:377-393. https ://doi.org/10.1111/j.0908-8857.2004.03378.x

Müller F, Taylor PD, Sjöberg S, Muheim R, Tsvey A, Mackenzie SA, Schmaljohann H (2016) Towards a conceptual framework for explaining variation in nocturnal departure time of songbird migrants. Mov Ecol 4:24. https://doi.org/10.1186/s4046 2-016-0089-2

Richards MP, McMurtry JP (2010) The avian proghrelin system. Int J Pept 2010. https://doi.org/10.1155/2010/749401 (Article ID 74940)

Schaub M, Jenni L, Bairlein F (2008) Fuel stores, fuel accumulation, and the decision to depart from a migration stopover site. Behav Ecol 19:657-666. https://doi.org/10.1093/beheco/arn023

Schmaljohann H (2018) Proximate mechanisms affecting seasonal differences in migration speed of avian species. Sci Rep 8(1):4106. https://doi.org/10.1038/s41598-018-22421-7

Schmaljohann H, Dierschke V (2005) Optimal bird migration and predation risk: a field experiment with northern wheatears Oenanthe oenanthe. J Anim Ecol 74:131-138. https://doi.org/1 0.1111/j.1365-2656.2004.00905.x

Schmaljohann H, Eikenaar C (2017) How do energy stores and changes in these affect departure decisions by migratory birds? A critical view on stopover ecology studies and some future perspectives. J Comp Physiol A 203:411-429. https://doi.org/10.1007/s0035 9-017-1166-8

Smith A, McWilliams S (2014) What to do when stopping over: behavioral decisions of a migrating songbird during stopover are dictated by initial change in their body condition and mediated by key environmental conditions. Behav Ecol 25(6):1423-1435. https:// doi.org/10.1093/beheco/aru148 
Tsvey A, Bulyuk VN, Kosarev V (2007) Influence of body condition and weather on departures of first-year European robins, Erithacus rubecula, from an autumn migratory stopover site. Behav Ecol Sociobiol 61:1665-1674. https://doi.org/10.1007/s0026 5-007-0397-z

Wingfield J, Schwabl H, Mattocks P (1990) Endocrine mechanisms of migration. In: Gwinner E (ed) Bird migration. Springer, Berlin, Heidelberg, pp 232-256
Publisher's Note Springer Nature remains neutral with regard to jurisdictional claims in published maps and institutional affiliations. 